\title{
Taiwan's technocrats stoke the economy
}

AMONG the rapidly growing number of returnees to Taiwan are many senior people who are taking up top positions in academia and government. They are also powering the development of new high-technology industries. In the 1950 s and 1960 s, the lack of postgraduate programmes in Taiwan left top graduates who wished to pursue further education with only one option: to go abroad. "At that time 95 per cent of my fellow physics students went to the United States," says Lih J. Chen, professor of materials science and engineering at the National Tsing Hua University, next to Hsinchu science-based industrial park. He returned to Taiwan in 1977 after ten years in the United States and receiving a PhD from the University of California at Berkeley.

\section{Brain drain benefits}

But Taiwan is now beginning to benefit from this brain drain as more and more senior researchers and engineers return from the United States and elsewhere. Taiwan's alumni club for Bell Laboratories of the United States boasts more than 200 members and some former returnees are reaching high political office. Taiwan's President Teng-Hui Lee received a $\mathrm{PhD}$ from Cornell University in agricultural economics in 1968, and many of the country's top science officials also have $\mathrm{PhDs}$ from universities in the United States.

Over the past few years, the number of senior returnees has reached "a critical mass" that will lead to rapid change, says Winston C. Y.Yu, Secretary General of the National Health Research Institutes, an ambitious new organization, established in January this year, which plans to emulate Britain's Medical Research Council and the US National Institutes of Health (see Nature 366, 500; 1993).

The country's rapid economic development and expanding postgraduate programmes have opened up new job opportunities for highly educated people. These, and a strong desire "to help out" and "make a contribution", are often cited as the prime motivation for returning.

The number of graduate students in Taiwan has increased more than tenfold from 3,912 in 1975 to 42,097 in 1995 . But Taiwan is still losing thousands of bright students to the United States each year, because living conditions are far from ideal and those in the forefront of research find "the standard in the US really much more exciting", one leading academic says.

The government's National Science
Council (NSC), which has five US offices (including one in Silicon Valley), is intensifying its efforts to encourage more of these students to return. In 1993, it set up a grants programme to help returnees to start their research quickly without competing headon with researchers already established in Taiwan. A total of 403 researchers was recruited under the programme in 1995 , and US\$12 million is allocated to recruit a similar number of "experts" in 1996.

The science-based industrial park in Hsinchu, also administered by the NSC, which has made Taiwan a world leader in the production of personal computers and integrated circuits, is continuing to attract returnees. The park, establised in 1980, has 193 companies, 81 set up by returnees. It is already in its third phase of development, and a fourth phase, as well as a second park in Tainan, southern Taiwan, is being planned by the NSC. Sales now exceed $\$ 11$ billion a year and the park, where 50,000 people (including 2,400 returnees) are employed, accounts for about 3 per cent of Taiwan's total manufacturing output.

\section{High-technology focus}

According to $\mathrm{H}$. Steve Hsieh, vice-chairman of the NSC, returnees with extensive experience in industry in the United States are helping transform Taiwan into "high-tech island" at a crucial time when more and more labour intensive light-industry is moving to the Chinese mainland. US companies and institutes are thus acting like "incubators" for Taiwan, he says.

The park and the nearby Industrial Technology Research Institute (ITRI), funded by the Ministry of Economic Affairs, have provided a huge impetus for Taiwan's booming integrated circuit industry. In fact, the industry is so successful that ITRI is having to search for a new purpose because industry no longer needs its support.

New types of companies are also emerging. In 1993, Peter Kuan, returned from the United States to set up Taiwan's first bioengineering company in the park, United Orthopedic Corporation. The company, which now employs 56 people, produces orthopedic implants designed especially for orientals and it hopes to export to other Asian markets, including China.

Genelabs Biotechnology is another ambitious new company at the park which hopes to win approval for Taiwan's first domestically-developed drug (most drugs produced in Taiwan are generics of drugs developed in the West). But Hsinchu's attempts to move into biotechnology have not yet been as successful as the integrated circuit industry, partly because top bioscientists are being attracted elsewhere in Taiwan. 